\title{
The Equity Myth: Racialization and Indigeneity at Canadian Universities. By Frances Henry, Enakshi Dua, Carl E. James, Audrey Kobayashi, Peter Li, Howard Ramos and Malinda S. Smith Vancouver, BC: UBC Press, 2017. ISBN: 9780774834896.
}

Across Canadian universities, the student population has become increasingly ethnically and racially diverse; yet, at the level of the professoriate, racialized and Indigenous scholars remain underrepresented. Despite the implementation of affirmative action programs, employment equity, and anti-discrimination policies, this underrepresentation has only intensified. Since universities are seen as a "bastion[s] of liberal democracy" (p. 3), the reality of racism within them is staunchly denied. However, as the essays in this needed book illustrate, the denial of racism also amounts to "the denial of equity" (p. 3).

This book is motivated by the disconcerting dearth of research on race and Indigeneity in the academy. In fact, "neither Statistics Canada nor the Canadian census publishes data on the percentages of racialized minorities in Canadian universities, either as faculty, staff, or students" (p. xviii). The Equity Myth - co-authored by Frances Henry, Enakshi Dua, Carl E. James, Audrey Kobayashi, Peter Li, Howard Ramos, and Malinda S. Smith—seeks to fill this knowledge gap. Conducted over a four-year period, this groundbreaking study is the first comprehensive, databased investigation that foregrounds the experiences and voices of racialized and Indigenous faculty in English-speaking Canadian universities. Using the prisms of critical race theory, whiteness studies, and intersectionality, Henry et al. critically examine the paradoxes surrounding the promise and myth of equity.

In the introductory chapter, Henry et al. guide the reader through their theoretical and conceptual influences (pp. 11-7) and methodologies (pp. 17-21). In chapters 2 and 3, the authors highlight the numerical underrepresentation of racialized and Indigenous professors. According to Henry and Kobayashi, a preliminary comparative analysis of American, British, and Australian universities indicates structural and institutional inequities similar to those found in Canada. In addition, Ramos and $\mathrm{Li}$ ascertain that the degree of underrepresentation faced by racialized scholars in academia is on the rise, and that on average, they are paid less than their white counterparts. Notably, the wage gap and problem of representation cannot easily be attributed to differences in human capital or productivity.

Chapters 4 through 7 focus on the stories and voices of racialized and Indigenous faculty. In addition to analyzing official census data, Ramos, James, Henry, and Kobayashi conduct an original online survey assessing the "outputs, outcomes, and perceptions of Canadian scholars" (p. 65), as well as more in-depth interviews with eighty-nine (forty-five women, forty-four men) racialized and Indigenous faculty (p. 94). These personal interviews, in particular, shine an important light on the "everyday racism" (Essed, 1991) experienced by racialized and Indigenous professors within academe. For example, after collecting data from eight Canadian universities, Ramos discovers that racialized academics learn to "play the game" by being "pragmatic and skeptical" about the devaluation of their labor and the efficacy of designated equity policies (p. 83). Furthermore, James observes that neoliberalism is creating "precarious work situations" (p. 86) for racialized and Indigenous scholars. Building on the work of Ahmed (2012) and Leonardo and Broderick (2011), he aptly elucidates that there is an "eregrious[ly] arbitrar[y]" (p. 90) "culture of whiteness" (p. 94) - intimately linked to a "culture of Journal of Contemporary Issues in Education, 2017, 12(2), pp. 50-52. 
homogenization" (p. 96) - that is "institutionalized" (p. 90). As such, racialized and Indigenous scholars are conditionally incorporated into the academy to "add color" (p. 90). Drawing on Essed's (1991) work on "everyday racism," Henry and Kobayashi (pp. 116-8) look beyond the statistical snapshots of underrepresentation to understand "who gets lost in the numerical shuffle" (p. 45). Namely, interviewees conveyed experiences of "loneliness," "alienation" (p. 118), and "tokenism" (p. 123). Henry and Kobayashi also address how racialized and Indigenous scholars navigate promotion and tenure processes, as well as epistemological racism.

Furthermore, James expounds on the complicated relationship racialized and Indigenous faculty—often viewed as "affirmative action hires" (p. 156) themselves - have with performing diversity work. James also explores how academic notions of merit are influenced by the idea of race and racial difference.

Chapters 8 through 11 provide an institutional analysis of inequity. Dua examines the proliferation of institutional structures that tackle anti-racism by identifying the contradictory deployment of "human rights," "equity," and "diversity" frameworks. Later, Dua investigates the success and/or limitations of policies and practices designed to address individual and systemic racism. It is important to note that, prior to this, there was "no systemic study of the effectiveness of equity policies in Canadian universities" (p. 208). Moreover, the human rights modelemployed by thirty-six out of the forty-nine universities sampled - is based on "provincial human rights codes that prohibit both discrimination and harassment in the workplace" (p. 177). Dua shows that human rights frameworks may be incommensurable with anti-racism because individual complaints of racism are delinked from institutional/systemic instantiations of racism. In addition, the "courts have also imposed different standards of evidence and law for racism than for gender-based complaints" (p. 215). Using the discipline of political science as a case study, Smith conducts a "diversity audit" (p. 248) in order to understand the intersectional relationship between race, Indigeneity, and gender. Furthermore, Smith identifies twelve unconscious race and gender biases that continue to be reproduced in academic spaces. For instance, she reveals that hiring practices are heavily influenced by "affinity bias" (p. 281) - the idea that individuals seek out others like themselves - and biases against "foreign" accents and non-Euro-American canonical knowledges. Lastly, in chapter 12, Henry et al. conclude with several policy points and future recommendations.

Throughout the book, there are several recurring themes that are particularly poignant for the future of racial equity in education. The first is the respondents' level of "ambivalence" toward the Canadian academic system, its equity policies, and diversity work. This "ambivalence" may be attributed to racialized and Indigenous faculty's ambiguous positioning within the academy. They are invited into academic spaces to "add color" (p. 90) and by " "being' diverse" (Ahmed, 2012, p. 43, emphasis added), yet are expected to leave their differing thoughts, histories, and methodologies at the door. Perhaps most troubling is that this book provides evidence that racialized and Indigenous professors are "presumed incompetent" (Gutiérrez y Muhs et al., 2012); they stand in front of the classroom, yet, are perplexingly seen as possessing no epistemic privilege. This was especially apparent when respondents discussed student evaluations (p. 140). Furthermore, their ambivalence can also be connected to the neoliberalization of the university. In particular, Dua's research illuminates the "complex relationship between neoliberalism and equity" (p. 204) whereby "diversity management" is presented as a way of dealing with or accommodating racial "difference" (p. 204).

Journal of Contemporary Issues in Education, 2017, 12(2), pp. 50-52. 
This book resonates deeply for me as a woman of color now enrolled in a graduate program in Canada. I have observed, anecdotally, that equity discussions and services are flourishing in universities. At the same time, I have noticed the tacit reconstitution and re-centering of whiteness in academe, for example when institutional equity gets reconfigured to focus on gender equity. Interestingly, several interviewees lamented that white female faculty mobilized against building a more expansive anti-racist human rights framework because they feared that gender equity may get lost in the process (pp. 194-196). In response, this book clearly argues that an understanding that racism and sexism are interlocking systems of oppression would make clear that the inclusion of racialized and Indigenous women demands a broader framework.

Overall, The Equity Myth illuminates the contradictions, paradoxes, and "shifting terrains" (p. 171) of the academy's "culture of whiteness." They clearly elucidate that within institutions of higher education, the culture of whiteness structures/reproduces inequalities; and that Canadian university spaces continue to marginalize racialized gendered Others. The authors further contend that the ineffectiveness of equity policies serves a vital function - "Not only do these policies serve as a mask, covering up discrimination, but they also offer a discursive performative process of naming 'not to effect'" (p. 238).

The Equity Myth must be read by university administrators who are interested in achieving racial justice. This book pushes administrators to go beyond paying "lip service" (pp. 34; 144) to diversity and to more precisely locate and undermine the culture of whiteness in their institutions. If we heed their caution, perhaps we may begin to move in a more equitable direction that creatively reimagines what bell hooks (1994) calls "education as the practice of freedom" (p. 6).

\section{References}

hooks, b. (1994). Teaching to transgress: Education as the practice of freedom. New York, NY: Routledge.

Reviewed by Jade How, Individualized Program, Concordia University

ja_how@alumni.concordia.ca 